\title{
Nugaros smegenų stimuliacija Lietuvoje, gydant polaminektominio sindromo skausmą
}

\author{
M. Vaišvilas* \\ A. Radžiūnas** \\ V. Deltuva** \\ A. Tamašauskas** \\ *Lietuvos sveikatos mokslu \\ universiteto ligonine, \\ Kauno klinikos, \\ Neurochirurgijos klinika \\ **Lietuvos sveikatos mokslu \\ universiteto ligonine, \\ Kauno klinikos, \\ Neurochirurgijos klinika; \\ Lietuvos sveikatos mokslu \\ universitetas, Medicinos akademija, \\ Neuromokslu institutas
}

\begin{abstract}
Santrauka. Lètinio neuropatinio skausmo gydymas yra aktuali problema, kurios efektyvus gydymas nèra lengvai pasiekiamas. Tokie pacientai dažnai tampa nedarbingi, susiduria su alinančiomis psichosocialinėmis problemomis. Lètinis neuropatinis skausmas po atliktos juosmens srities stuburo operacijos priskiriamas polaminektominiam sindromui. Esant neefektyviam gydymui šiuolaikinèmis skausmo gydymo priemonėmis, gali būti taikoma nugaros smegenų stimuliacija. Nors šio gydymo metodo efektyvumas ịrodytas ir plačiai taikomas įvairiose šalyse, Lietuvoje toks gydymo metodas yra sunkiai pasiekiamas pacientui, susiduriančiam su nekontroliuojamu skausmu. Šiame straipsnyje aprašomas klinikinis atvejis 55 metų vyro, gydyto LSMUL Kauno klinikose dèl polaminektominio sindromo, taikant nugaros smegenų stimuliaciją.
\end{abstract}

Raktažodžiai: polaminektominis sindromas, lètinis neuropatinis skausmas, nugaros smegenų stimuliacija.

\section{IVADAS}

Juosmens srities skausmas yra plačiai paplitusi visuomenės problema, turinti neigiamą socialinę, psichologinę ir finansinę įtaką paciento gyvenimui. Senstant visuomenei, vis daugiau pacientų skundžiasi nugaros skausmu. Šio nusiskundimo dažnis sudaro apie $9,4 \%$ pasaulio populiacijos ir sukelia didžiausią neiggalumo dali [1]. Didejjant ligos atvejų skaičiui, daugejja pacientų, operuojamų dèl juosmeninès stuburo patologijos. Tačiau ne visiems pacientams po atliktos sėkmingos stuburo juosmeninès srities operacijos skausmas išnyksta. Literatūros duomenimis, nuo 10 iki $40 \%$ pacientų po atliktos vienos ar kelių juosmens srities

\footnotetext{
Adresas:

Mindaugas Vaišvilas

Lietuvos sveikatos mokslu universiteto ligonine.

Neurochirurgijos klinika

Eiveniu g. 2, LT- 44136 Kaunas

El.paštas mindaugas.vaisvilas@gmail.com
}

operacijų išlieka lėtinis neuropatinis skausmas, sukeliantis negalią [2]. Neuropatinis skausmas - tai skausmas, kurio priežastis yra nervų sistemos pažaida ar disfunkcija. Neuropatiniam skausmui priskiriamas polaminektominis sindromas (PLS) ir kompleksinis regioninis skausmo sindromas (KRSS).

\section{POLAMINEKTOMINIS SINDROMAS}

PLS, pirmą kartą paminėtas Follet ir Dirks 1993 m., siejamas su priešoperaciniais ir pooperaciniais rizikos faktoriais.

\section{PRIEŠOPERACINIAI PLS RIZIKOS FAKTORIAI}

Vienas svarbiausių priešoperacinių PLS rizikos faktorių yra tikslios diagnozès ir indikacijų operaciniam gydymui nustatymas. Iki 58 \% PLS sudaro nenustatyta lateralinė

(C) Neurologijos seminarai, 2018. Open Access. This article is distributed under the terms of the Creative Commons Attribution 4.0 International License CC-BY 4.0 (http://creativecommons.org/licenses/by/4.0/), which permits unrestricted use, distribution, and reproduction in any medium, provided you give appropriate credit to the original author(s) and the source, provide a link to the Creative Commons license, and indicate if changes were made. 
stuburo kanalo stenozė [3]. Kitas pavyzdys - atliekama diskektomija dèl nenustatytos Clunealis kompresinès neuropatijos [4].

Psichologiniai faktoriai taip pat gali nulemti paciento pooperacines išeitis. Atliktuose tyrimuose pastebèta, kad pacientai, sergantys depresija, skundžiasi didesniu nuovargiu ir negalia, jų darbingumo atsistatymas trunka ilgiau nei pacientų, kuriems depresija nediagnozuota [5, 6].

Prospektyvinė studija nustate, kad, po operacijos praejjus dvejiems metams, rūkančių pacientų gyvenimo kokybė yra prastesné, didesnis vartojamų analgetikų kiekis ir prastesnès eisenos atsistatymo galimybės nei nerūkančiųu [7].

Neigalumo pašalpų gavimas gali turèti įtakos paciento motyvacijai sveikti po operacijos. Kelios studijos palygino pacientus, gaunančius ir negaunančius pašalpas: pastebėtas didesnis analgetikų vartojimas, blogesnis funkcijos atsistatymas ir prastesnis emocinis statusas tarp gaunančiu neicgalumo pašalpas pacientų $[6,8,9]$.

\section{POOPERACINIAI PLS RIZIKOS FAKTORIAI}

Pooperaciniams rizikos faktoriams priskiriami po operacijos atsirandantys juosmens srities mioskeletinių struktūrų pakitimai. Dèl pakitusių biomechaninių savybių po chirurginès intervencijos gali atsirasti raumenų pertempimas, spazmavimas, nuovargis, vedantys ị lètinị juosmens skausmą po operacijos [10]. Operacijos metu naudojama fiksacija gali pakeisti sagitalinị balansą, dèl ko gali atsirasti aukščiau ir žemiau fiksuoto segmento degeneracinių pakitimų [11]. Po operacijos atsirandantys randiniai pakitimai gali daryti ịtaką kanalo stenozei [12].

Atlikus prospektyvinę studiją, kurios metu operuota 260 pacientų dèl degeneracinès juosmeninès stuburo kanalo stenozès, atliekant laminektomiją ar laminektomiją su spondilodeze, 29,2 \% pacientų, po operacijos praejus metams, skausmas nepasikeitė ar netgi padidejo [13]. Sisteminè diskektomijų dèl juosmeninės disko išvaržos apžvalga parodė 5-36 \% išliekanti juosmens ar kojos skausmą po 2 metų [14]. Jei po juosmeninès srities patologijos operacijos išlieka tokio pat pobūdžio simptomatika, pirmiausia reikètu atmesti nepakankamos operacijos apimties galimybę. Naujo pobūdžio simptomatika gali būti sukelta migravusio sraigto, pooperacinio pakraujavimo, vėlyvesniame periode - ir supuražo.

Diagnozei patikslinti yra tikslingi radiologiniai tyrimai. Atliktos funkcinès spondilogramos gali parodyti sagitalinio balanso pasikeitimą, atsiradusias naujas deformacijas, nestabilumą. Minkštụjų audinių komponentai gerai matomi magnetinio rezonanso tyrimo metu, kada tikslinga diferencijuoti tarp disko išvaržos recidyvo ar pooperacinių radinių pakitimų. Ypač svarbi yra kompiuterinė tomografija, kuri gerai vizualizuoja kaulinių struktūrų pokyčius.

Pacientai, patiriantys lètinį neuropatinį skausmą, kenčia nuo fiziologinių ir psichologinių pokyčių (miego sutrikimas, dirglumas, priklausomybė nuo vaistų, nedarbingumas).

\section{INDIKACIJOS NSS}

Lètiniam skausmui gydyti sudaromas individualus gydymo planas, apimantis farmakologinį gydymą, chirurgines intervencijas, psichologinę ir fizinę terapiją. Tik esant neefektyviam minètam gydymui gali būti pasirenkama nugaros smegenų stimuliacija (NSS), kaip dalis gydymo plano, su kitomis terapinėmis priemonėmis.

NSS gali būti taikoma, kai:

- lètinis skausmas - nuo 5 balų (pagal VAS), trunka ilgiau nei 6 mẻn., taikant adekvatų skausmo gydymą,

- nèra stuburo srities aiškios patologijos, galinčios sukelti skausmą,

- skausmo priežastis nėra onkologinė liga,

- skausmo priežastis nèra išeminė liga (išskyrus klinikinių tyrimų atvejais),

- nėra priklausomybės nuo skausmą malšinančių vaistų,

- nèra gretutinès sunkios psichiatrinès patologijos.

NSS taikoma tik įvertinus multidisciplininei komandai, kuri turi patirties gydant lètinị skausmą, pacientus su NSS ir kuri gali atlikti tolimesni paciento stebejjimą bei suteikti reikiamą pagalbą po NSS. Būtina atlikti ir bandomają stimuliaciją prieš ilgalaikio stimuliatoriaus implantavimą. Siekiant geriausių NSS rezultatų, ji turi būti taikoma tik centruose, turinčiuose patirtị gydant ligonius su neuromoduliacija.

\section{NSS VEIKIMAS}

Nugaros smegenų stimuliacijos veikimo principas grindžiamas skausmo suvokimo pakeitimu parestezija [15] Tačiau ne visiems pacientam atsiradusi parestezija yra toleruojamas pojūtis. Naujos technologijos atveria galimybes platesniam NSS panaudojimui. Nugarinių šaknelių mazgo stimuliacija leidžia selektyviai pasirinkti skausmo malšinimo zonas [15]. Taikoma $10000 \mathrm{~Hz}$ dažnio stimuliacija nesukelia parestezijos pojūčio ir sėkmingai malšina skausmą [16]. Pulsinė stimuliacija taikoma penkiais pulsais po $40 \mathrm{~Hz}$, su pulsų dažniu $500 \mathrm{~Hz}$. Tokios stimuliacijos rezultatas - sumažinta arba nejaučiama parestezija [17].

Atlikti du randomizuoti kontroliniai tyrimai, vertinantys PLS gydymą, taikant NSS.

PROCESS tyrimo metu nustatytas statistiškai reikšmingas skausmo sumažėjimas $50 \%$ po 6 mèn. NSS grupėje $48 \%$ pacientų, lyginant su $9 \%$, taikant adekvatų skausmo gydymą (ASG). Po 12 mėnesių - $34 \%$ ir $7 \%$ NSS ir ASG grupėse atitinkamai. Nustatytas statistiškai reikšmingas funkcijos pagerẻjimas, naudojant Oswestry disability Index, NSS grupeje, lyginant su ASG [18].

Nugaros smegenų stimuliatoriaus sistema sudaryta iš keturių komponentų:

- neurostimuliatorius su baterija, generuojantis elektros impulsus arba priimantis radiodažnio bangas;

- elektrodai (nuo 8 iki 32), implantuojami epiduraliai virš nugaros smegenų; 
- konektorius, jungiantis elektrodus su neurostimuliatoriumi;

- nuotolinio valdymo pultas, skirtas nustatyti tinkamus stimuliavimo parametrus.

Baterija gali būti pakraunama arba nepakraunama. $\mathrm{Pa}-$ kraunama baterija tarnauja iki 8-10 metų, tačiau reikalingas nuotolinis jos krovimas bent kartą per savaitę. Nepakraunamą bateriją reikia keisti po 2-5 metų.

Elektrodai gali būti cilindriniai arba gardeliniai. Nuo elektrodų tipo priklauso implantavimo technika.

- Cilindrinius elektrodus galima implantuoti perkutaniškai, tačiau yra didesnè elektrodų migravimo tikimybė, dẻl ko gali būti reikalinga didesnè stimuliavimo srovè ir greičiau iškraunama baterija. Esant reikalui, šiuos elektrodus lengva pašalinti.

- Gardeliniai elektrodai turi plokščią formą ir sudaryti nuo 2 iki 5 elektrodų kolonų. Implantuojami atliekant hemilaminotomiją, todèl juos galima fiksuoti ir sumažinti migravimo tikimybę. Šie elektrodai leidžia pasiekti skausmą malšinantị efektą mažesnèmis amplitudèmis nei cilindriniais elektrodais, tačiau jų implantavimą vietose, kur yra siauresnis stuburo kanalas, riboja didesni matmenys.

Kiekvienam pacientui būtina bandomoji stimuliacija prieš implantuojant ilgalaikị stimuliatorių. Bandomoji stimuliacija atliekama naudojant perkutaninius elektrodus, kurie ịvedami vietinejje nejautroje per epidurinę adatą. Elektrodai prijungiami prie išorinio arba implantuojamo stimuliatoriaus. Bandomoji stimuliacija trunka nuo 3 iki 7 dienų. Tuo metu sprendžiama, ar toks gydymo metodas yra tinkamas atrinktam pacientui. Stimuliacija laikoma sėkminga, kai pasiekiamas bent $50 \%$ skausmo sumažejjimas su padidẻjusiu paciento aktyvumu ir sumažejusiomis nuskausminamujų vaistų dozėmis. Po bandomosios stimuliacijos elektrodai pašalinami. Ilgalaikis stimuliatorius implantuojamas praejjus bent kelioms savaitèms, ịsitikinus, kad nèra infekcijos. Jei stimuliacija neduoda patenkinamo skausmą malšinančio efekto, elektrodai pašalinami, nesukeliant pažaidos.

Gydomo skausmo lokalizacija ir pasirinkto elektrodo tipas apsprendžia operacijos lygmenị. Naudojant perkutaninę sistemą, elektrodus galima pastumti kranialyn nuo ivvedimo lygmens. Implantuojant gardelinius elektrodus, operacija atliekama stimuliuojamame lygmenyje. Dažniausiai naudojami lygmenys, priklausomai nuo skausmo lokalizacijos [19]:

- kaklas - virš C3,

- petys - virš C5,

- ranka - C5-6,

- šlaunis: priekinis paviršius - T7-8, užpakalinis T11-L1,

- pèda - L1,

- juosmuo - T9-10.

Elektrodai implantuojami paprastai vietinejje nejautroje. Pacientui būdraujant ir bendraujant su juo, nustatomas tinkamas elektrodų implantavimo lygmuo. Taikant bendrinę nejautrą, išlieka rizika pažeisti nervines struktūras, kas gali išryškèti tik po operacijos išbudinus pacientą.

\section{KLINIKINIS ATVEJIS}

LSMUL Kauno klinikose gydytas 55 metų amžiaus vyras, kuris nurodè 8-10 balų (pagal VAS) juosmens ir kairès kojos skausmą šlaunies užpakaliniame paviršiuje, tris kartus operuotas dèl stuburo lumbosakralinès srities nestabilumo (atlikta užpakalinė spondilodezė su segmentine vidine stuburo fiksacija (angl. PLIF) ir tarpketerinè („Coflex“) stabilizacija). Po atliktų operacijų skausmingumas išliko nepakitęs. Vèliau pašalintas "Coflex“ implantas (1 pav.). Gydymas, taikytas skausmo klinikoje, taip pat neefektyvus. Naudojami opioidiniai analgetikai mažai efektyvūs. Atliktuose radiologiniuose tyrimuose aiškios patologijos, indikuojančios chirurginę intervenciją, nenustatyta.

Bendra būklè - patenkinama, be sunkių gretutinių patologijų. Pacientui ịvertinta HAD skalè: 13:11, emocinè būklè subkompensuota. Multidisciplininė komanda, sudaryta iš neurochirurgo, skausmo gydytojo ir klinikinio psichologo, ịvertinusi nutarè, kad nugaros smegenų stimuliatoriaus implantavimas šiam pacientui yra tinkamas.

Pacientui atlikta bandomoji stimuliacija. Vietineje ir intraveninejje nejautroje pacientui implantuotas perkutaninis 8 kontaktų epiduralinis elektrodas „St. Jude“, paliekant elektrodą ties Th10-12 lygmeniu (2A, 2B pav.). Per prailgintoją išvestas i i išorę, prijungtas prie neurostimuliato-

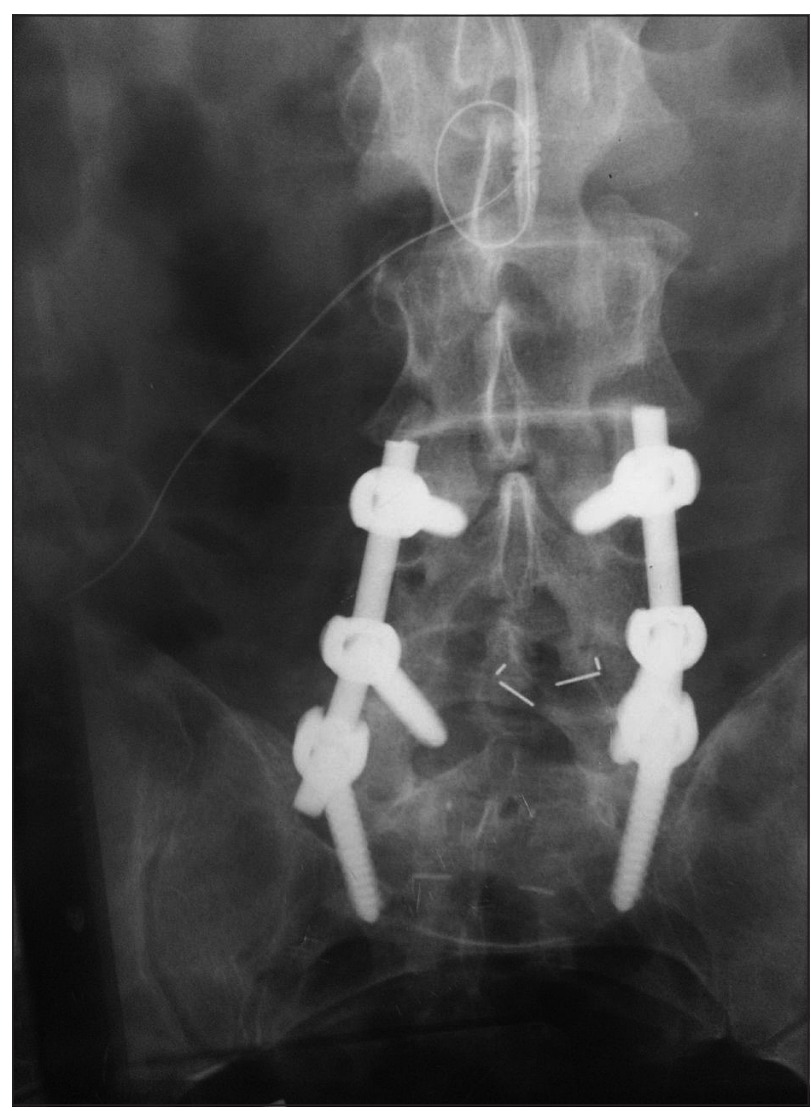

1 pav. Paciento spondilograma po atliktos užpakalinės spondilodezės su segmentine vidine stuburo fiksacija. „Coflex“ implantas pašalintas 


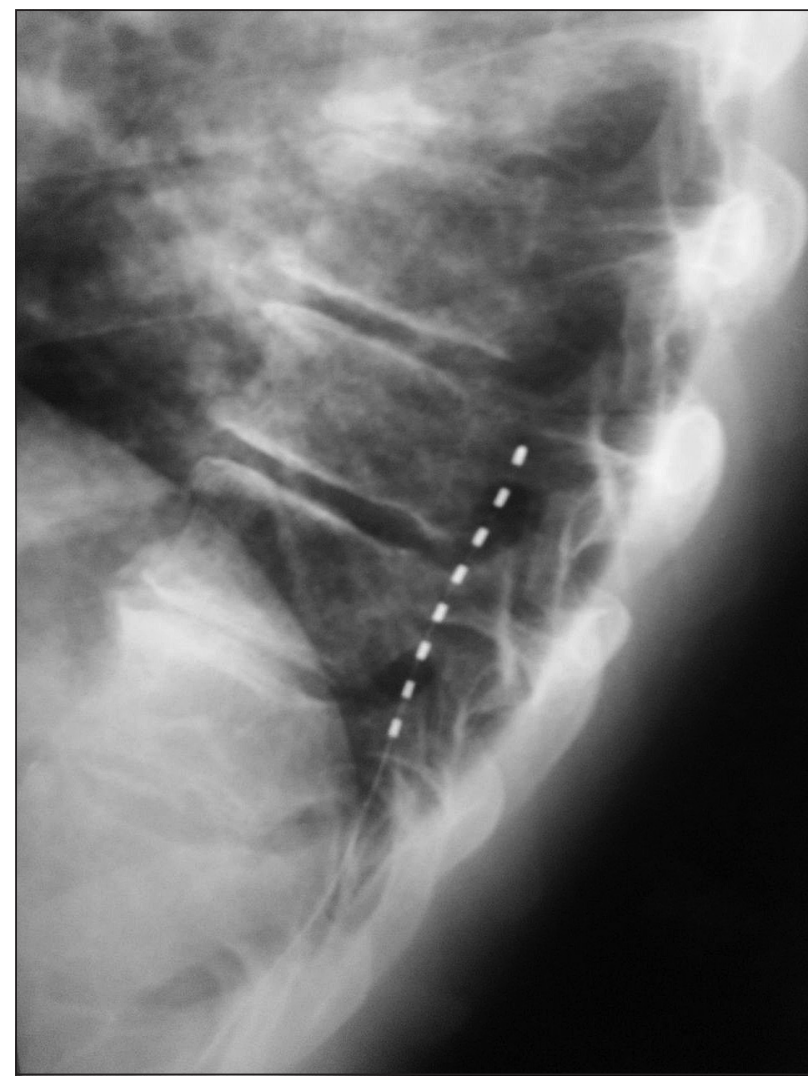

2A pav. Bandomosios stimuliacijos elektrodas ties Th10-12. Šoninė projekcija

riaus. Atliktas pirminis bipoliarinis stimuliavimas $60 \mathrm{~Hz}$, $210 \mathrm{~ms}, 1,8-4,2 \mathrm{~mA}$. Stimuliavimo efektas - geras, apimtas L4-L5 dermatomas kairẻje. Po dešimties dienų bandomosios stimuliacijos skausmas kojoje sumažèjo iki 1 balo (pagal VAS), juosmenyje - 4 balai. Pasiektas skausmo sumažejimas stimuliuojant $>50 \%$ pagal VAS. Bandomoji stimuliacija buvo sėkminga, todèl pacientui implantuotas nuolatinis "Genesis“ neurostimuliatorius. Tačiau po operacijos išryškèjo pasikeitusi stimuliacijos lokalizacija. Rentgenologiškai - migravęs epidurinis elektrodas kranialyn, reikalaujantis revizijos, elektrodo lokalizacijos atstatymo ị pradinị lygmenị. Po atliktos operacijos eiga sklandi, skausmas sumažèjo iki prieš tai buvusio lygmens. Pacientas išrašytas tolimesniam ambulatoriniam gydymui.

Po dvejų metų stimuliatoriaus baterija išsikrovè, atsinaujino kojos skausmas - iki 6-7 balų, juosmens - iki 8 balų pagal VAS.

Pacientui nuspręsta implantuoti 16 kontaktų elektrodą su pakraunamu stimuliatoriumi. Pašalinus seną stimuliatorių, bendrinejje nejautroje atlikta hemilaminektomija Th10 lygmenyje, rezekavus geltonaji raištic epiduraliai ivestas 16 kontaktų „Penta“ elektrodas ties Th9 slankstelio kūnu (3 pav.). Atlikus bandomają stimuliaciją, įvertintas stimuliavimo efektas. Kairès kojos skausmas sumažejo iki 1 balo pagal VAS. Juosmens skausmas - iki 5 balų pagal VAS. Pacientui implantuotas nuolatinis pakraunamas neurostimuliatorius „Prodigy“. Taikytas stimuliavimas bipo-

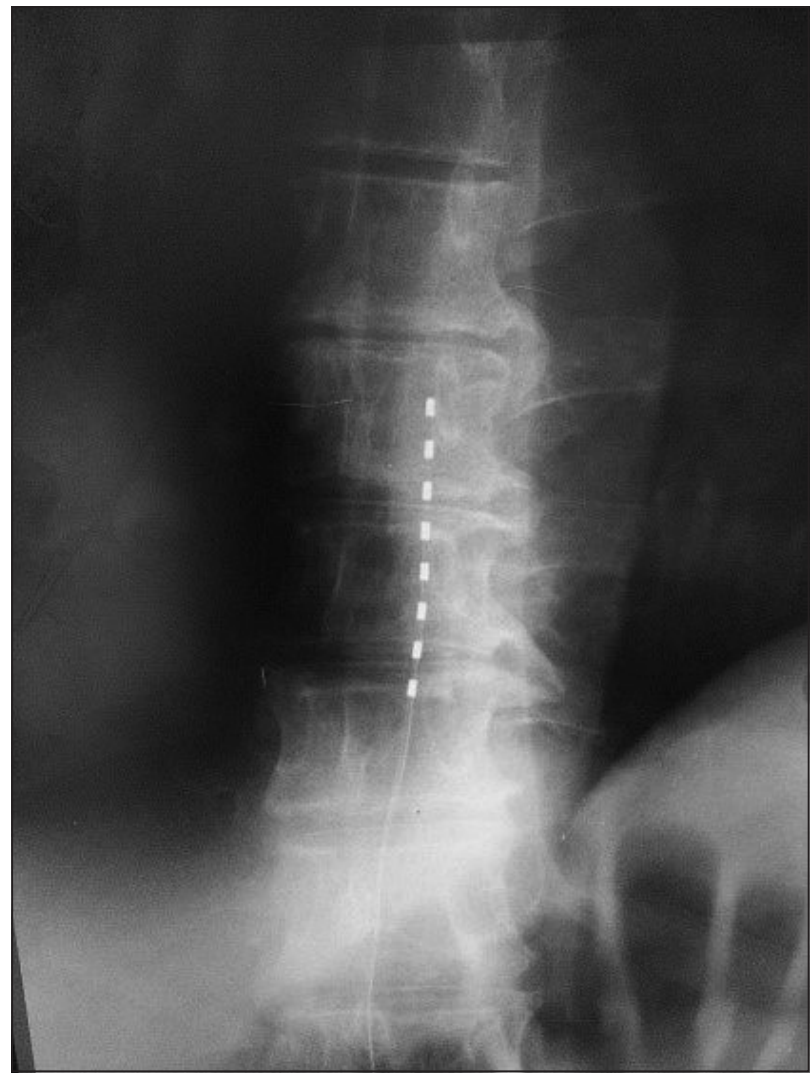

2B pav. Bandomosios stimuliacijos elektrodas ties Th10-12. Priekinė projekcija

liu režimu $50 \mathrm{~Hz}, 320 \mathrm{~ms}, 7,8-11,5 \mathrm{~mA}$ srove. Stimuliavimo efektas geras. Parestezija L1-L4 dermatomuose abipus.

Pacientas išrašytas ambulatoriniam gydymui. Gydymo eigoje sumažejo vartojamų analgetikų dozès.

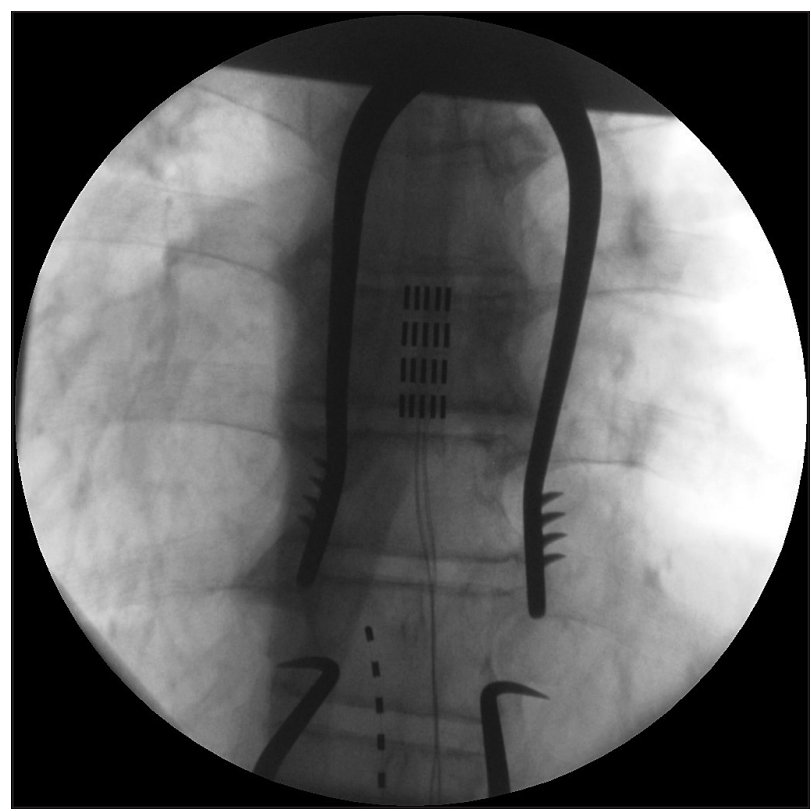

3 pav. Gardelinio tipo elektrodas implantuotas epiduraliai ties Th9 lygmeniu 


\section{APIBENDRINIMAS}

Lètinio neuropatinio polaminektominio sindromo skausmo gydymas, atliekant nugaros smegenų stimuliaciją, yra efektyvus šiuolaikinis gydymo metodas tinkamai parinktiems pacientams.

Neuropsichologinis ištyrimas yra labai svarbus, atrenkant pacientą neurostimuliacijai. Rekomenduojama tirti pacientą dèl emocinio stabilumo ir depresijos [20]. Kiekybinis jutimo tyrimas gali būti naudojamas individualiam kiekybiniam paciento skausmo suvokimo nustatymui. Padidejęs jautrumas arba sumažejjęs skausmo slenkstis yra galimi rizikos veiksniai blogiems operacijos rezultatams $[21,22]$. Būtina įvertinti depresiją su daugiafaziu asmenybės aprašu. Skausmas vertinamas validizuotais skausmo klausimynais [23]. Svarbu žinoti, kad emocinè būsena ir gebejjimas gyventi su skausmu turi įtakos stimuliacijos rezultatams [24]. Taip pat siūloma taikyti kognityvinę elgsenos terapiją prieš implantuojant stimuliatorių.

Kiekvienam pacientui, kurio lètinio neuropatinio skausmo gydymas šiuolaikinėmis skausmo gydymo priemonėmis yra neefektyvus, kuriam atliktas neuropsichologinis ištyrimas ir nėra absoliučių kontraindikacijų chirurginei intervencijai, būtina atlikti bandomają NSS. Tik jos metu galima nuspręsti, ar skausmo gydymas nugaros smegenų stimuliacija yra tinkamas konkrečiu atveju.

Implantuojant elektrodus, galima rinktis iš kelių elektrodų variantų, kurie turi savų pliusų ir minusų. Nèra nustatyta tikslių gairių, koks elektrodas tinkamas kiekvienam pacientui, todèl svarbu atlikti bandomąą stimuliaciją, esant reikalui pakeičiant elektrodo padètic ar elektrodo kontaktų skaičių, kol gaunamas reikiamas efektas.

Implantuojami perkutaniniai elektrodai daugeliu atvejų atrodo patraukliai dèl minimaliai invazyvaus jų implantavimo būdo, tačiau naudojama didesnè stimuliacijos srovẻ ir išliekanti elektrodų migravimo galimybẻ turi būti aptarta su ligoniu. Gardelinis elektrodas implantuojamas atveriant stuburo kanala per hemilaminektomiją, tačiau tikslus jo implantavimas ir galimybė patikimai fiksuoti leidžia tikètis ilgesnio neurostimuliatoriaus baterijos tarnavimo laiko bei efektyvaus platesnès skausmo zonos stimuliavimo.

\section{Literatūra}

1. Hoy D, March L, Brooks P, Blyth F, Woolf A, Bain C, et al. The global burden of low back pain: estimates from the Global Burden of Disease 2010 study. Ann Rheum Dis 2014; 73(6): 968-74. https://doi.org/10.1136/annrheumdis-2013204428

2. Kumar K, Malik S, Demeria D. Treatment of chronic pain with spinal cord stimulation versus alternative therapies: cost-effectiveness analysis. Neurosurgery 2002; 51(1): 106-15. https://doi.org/10.1097/00006123200207000-00016

3. Burton CV, Kirkaldy-Willis WH, Yong-Hing K, Heithoff KB. Causes of failure of surgery on the lumbar spine. Clin Orthop Relat Res 1981; 157: 191-9. https://doi.org/10.1097/00003086-198106000-00032
4. Kuniya H, Aota Y, Kawai T, Kaneko K, Konno T, Saito T. Prospective study of superior cluneal nerve disorder as a potential cause of low back pain and leg symptoms. J Orthop Surg Res 2014; 9(1): 139. https://doi.org/10.1186/ s13018-014-0139-7

5. Anderson JT, Haas AR, Percy R, Woods ST, Ahn UM, Ahn NU. Clinical depression is a strong predictor of poor lumbar fusion outcomes among workers' compensation subjects. Spine 2015; 40(10): 748-56. https://doi.org/10.1097/ BRS.0000000000000863

6. McKillop AB, Carroll LJ, Battié MC. Depression as a prognostic factor of lumbar spinal stenosis: a systematic review. Spine J 2014; 14(5): 837-46. https://doi.org/10.1016/ j.spinee.2013.09.052

7. Sandén B, Försth P, Michaèlsson K. Smokers show less improvement than nonsmokers two years after surgery for lumbar spinal stenosis. Spine 2011; 36(13): 1059-64. https://doi.org/10.1097/BRS.0b013e3181e92b36

8. Gum JL, Glassman SD, Carreon LY. Is type of compensation a predictor of outcome after lumbar fusion? Spine 2013; 38(5): 443-8. https://doi.org/10.1097/BRS. 0b013e318278ebe8

9. Nguyen TH, Randolph DC, Talmage J, Succop P, Travis R. Long-term outcomes of lumbar fusion among workers' compensation subjects. Spine 2011; 36(4): 320-31. https://doi.org/ 10.1097/BRS.0b013e3181ccc220

10. Rigoard P, Blond S, David R, Mertens P. Pathophysiological characterisation of back pain generators in failed back surgery syndrome (part B). Neurochirurgie 2015; 61: S35-44. https://doi.org/10.1016/j.neuchi.2014.10.104

11. Arts MP, Kols NI, Onderwater SM, Peul WC. Clinical outcome of instrumented fusion for the treatment of failed back surgery syndrome: a case series of 100 patients. Acta Neurochir (Wien) 2012; 154(7): 1213-7. https://doi.org/ 10.1007/s00701-012-1380-7

12. Hsu E, Atanelov L, Plunkett AR, Chai N, Chen Y, Cohen SP. Epidural lysis of adhesions for failed back surgery and spinal stenosis. Anesth Analg 2014; 118(1): 215-24. https://doi.org/10.1213/ANE.0000000000000042

13. Skolasky RL, Wegener ST, Maggard AM, Riley LH. The impact of reduction of pain after lumbar spine surgery. Spine 2014; 39(17): 1426-32. https://doi.org/10.1097/BRS. 0000000000000428

14. Parker SL, Mendenhall SK, Godil SS, Sivasubramanian P, Cahill K, Ziewacz J, et al. Incidence of low back pain after lumbar discectomy for herniated disc and its effect on patientreported outcomes. Clin Orthop Relat Res 2015; 473(6): 1988-99. https://doi.org/10.1007/s11999-015-4193-1

15. Deer TR, Krames E, Mekhail N, Pope J, Leong M, StantonHicks M, et al. The appropriate use of neurostimulation: new and evolving neurostimulation therapies and applicable treatment for chronic pain and selected disease states. Neuromodulation Technol Neural Interface 2014; 17(6): 599-615. https://doi.org/10.1111/ner.12204

16. Kapural L, Yu C, Doust MW, Gliner BE, Vallejo R, Sitzman BT, et al. Novel $10-\mathrm{kHz}$ high-frequency therapy (HF10 therapy) is superior to traditional low-frequency spinal cord stimulation for the treatment of chronic back and leg pain. Anesthesiology 2015; 123(4): 851-60. https://doi.org/ 10.1097/ALN.0000000000000774

17. De Ridder D, Plazier M, Kamerling N, Menovsky T, Vanneste S. Burst spinal cord stimulation for limb and back pain. World Neurosurgery 2013; 80(5): 642-9.e1. https://doi.org/10.1016/.wneu.2013.01.040 
18. Manca A, Kumar K, Taylor RS, Jacques L, Eldabe S, Meglio M, et al. Quality of life, resource consumption and costs of spinal cord stimulation versus conventional medical management in neuropathic pain patients with failed back surgery syndrome (PROCESS trial). Eur J Pain 2008; 12(8): 1047-58. https://doi.org/10.1016/j.ejpain.2008.01.014

19. Barolat G, Massaro F, He J, Zeme S, Ketcik B. Mapping of sensory responses to epidural stimulation of the intraspinal neural structures in man. J Neurosurg 1993; 78(2): 233-9. https://doi.org/10.3171/jns.1993.78.2.0233

20. Doleys DM. Psychological factors in spinal cord stimulation therapy: brief review and discussion. Neurosurg Focus 2006; 21(6): E1. https://doi.org/10.3171/foc.2006.21.6.4

21. Granot M. Can we predict persistent postoperative pain by testing preoperative experimental pain? Curr Opin Anaesthesiol 2009; 22(3): 425-30. https://doi.org/10.1097/ ACO.0b013e32832a40e1

22. Eisenberg E, Backonja M-M, Fillingim RB, Pud D, Hord DE King GW, et al. Quantitative sensory testing for spinal cord stimulation in patients with chronic neuropathic pain. Pain Pract 2006; 6(3): 161-5. https://doi.org/10.1111/ j.1533-2500.2006.00080.x

23. Burchiel KJ, Anderson VC, Wilson BJ, Denison DB, Olson KA, Shatin D. Prognostic factors of spinal cord stimulation for chronic back and leg pain. Neurosurgery 1995; 36(6): 1101-10. https://doi.org/10.1097/00006123 199506000-00006

24. Sparkes E, Duarte RV, Raphael JH, Denny E, Ashford RL. Qualitative exploration of psychological factors associated with spinal cord stimulation outcome. Chronic Illn 2012; 8(4): 239-51. https://doi.org/10.1177/1742395311433132

M. Vaišvilas, A. Radžiūnas, V. Deltuva, A. Tamašauskas

FAILED BACK SURGERY SYNDROME TREATMENT USING SPINAL CORD STIMULATION IN LITHUANIA

\section{Summary}

Treatment of chronic neuropathic pain is a devastating problem when proper symptom relief is hardly achievable. Many of the treated patients become unable to work because of their disability and face psychosocial problems. Failed Back Surgery Syndrome is defined as persisting chronic neuropathic pain after a successful lumbar spine surgery. Spinal cord stimulation remains a treatment option when modern pain treatment modalities fail. Although such treatment's efficacy is proved and it is used globally, in Lithuania very few patients can benefit from such treatment. In this article we describe a 55-year-old male patient, treated for Failed Back Surgery Syndrome using spinal cord stimulation in The Hospital of Lithuanian University of Health Sciences (LSMU) Kauno klinikos.

Keywords: failed back surgery syndrome, chronic neuropathic pain, spinal cord stimulation.

Gauta:

20180514
Priimta spaudai: 20180527 